\title{
Importance of English in Engineering for Professional Communication: A Study in the Nepalese Context
}

\author{
Rup Narayan Shrestha ${ }^{1}$, Bharat Raj Pahari ${ }^{1}$, Jai Raj Awasthi ${ }^{2}$ \\ ${ }^{1}$ Pulchowk Campus, Institute of Engineering, Tribhuvan University, Nepal \\ ${ }^{2}$ Far-western University, Kathmandu, Nepal \\ Corresponding author: rupnarayan_sth@hotmail.com
}

Received: July 9, 2016 Revised:Aug. 13, 2016 Accepted: Aug. 25, 2016

\begin{abstract}
This article attempts to highlight the importance of English in the professional communication in the field of engineering in Nepal. The main objective of the article is to shed light on the role English language plays in the communication related to engineering. Based primarily on the review of some relevant literature available, the present article reveals the fact that English being one of the global languages used in a wide range of communicative fields all over the world, it serves as an important tool for professional communication in engineering in Nepal.
\end{abstract}

Key words: English language, communication, engineering, professional

\section{Introduction}

As communication is one of the universal traits of human beings, it is almost impossible for any human beings to survive in this complex world without it. Undoubtedly, communication enables the participants to share their experiences and feelings with each other. Language is the most common means of human communication. People in different communities with professions use different varieties of languages according to their community, culture and the nature of their profession. Engineering, which has international link, needs a language that has a global access. In the present day world of globalization, English which serves as a primary/ popular global language can be the only convenient means of professional communication for engineering professionals.

The present paper is intended for shedding light on the importance of English as a means of professional communication in the field of engineering in Nepal. Broadly, it encompasses a wide range of sub-headings such as definition of communication, communication and profession, communication and professionals, English as a means of global communication, English as a means of Communication in Nepal, English as a means of communication in engineering, English for the employability of engineering graduates, and English for the execution of engineering jobs respectively.

\subsection{Definition of Communication}

Communication is a process of exchanging or transmitting messages between sender and receiver. There are different kinds of communication: interpersonal communication, intrapersonal 
communication, verbal communication, non-verbal communication, written communication, oral communication, and so on. We can also have general communication and technical communication. No matter whichever form of communication it might be, the most important purpose of communication is to exchange message, ideas, feelings, and experiences between the participants. Language is used in most of the communications except in non-verbal communication. Among various systems and methods of communication, human communication system especially human language is unique. Hurford [4] remarks, "Although every communication system can claim in some way to be unique, human language is spectacularly unique in its complexity and expressive power" (p. 249).

\subsection{Communication and Profession}

Communication has a very important place in any profession. It is almost impossible to handle any profession in the world in the absence of communication. In all kinds of professions, communication plays a vital role. Success depends greatly on the communication skills of the professionals. Konar [8], emphasizes that in today's competitive and globalized world, communication has become an essential tool for everyone, be they students, academics or professionals. For the professionals, effective communicative skill is of prime importance. It is the basic requirement for them. In the words of Konar [8], "For technocrats and professionals, it becomes all the more necessary to acquire good communication skills as they have to communicate effectively with all their business and professional colleagues."

The professionals spend a great deal of their time communicating with their partners, employees, clients and colleagues. In a professional world, what professionals do most of the time is to communicate [Kumar \& Lata, 9]. It is the communication that determines the success and failure of any profession. Those companies and organizations which have the employees possessing good communication skills can perform better. In the absence of proper kind of communication skills in the professionals, it is difficult for any organization to survive. As Kumar and Lata [9] put it, "It is communication that propels the management process and serves as the lubricant for its smooth operation" (P.2).

\subsection{Communication and Professionals}

Any professional individual needs a fairly good communication skill for enabling him or her to perform the job in a most effective manner. Communicative skills of the professionals determine their employment opportunity and the sustenance of their job. Those who lack sufficient communicative skills neither get job nor can they sustain even after they manage to get it as the effectiveness of their performance is fully dependent on how capable they are in meaningful and effective communication. According to Sanjaya Kumar and Pushpa Lata [9],"Communication in the professional world occupies such a pivotal position that there hardly exists an activity in the business and industry that does not require communication to play any role" (P.2). In the words of Kumar and Lata [9], "Communication helps professionals in their five major managerial tasks namely planning, organizing, executing, staffing and controlling" (P.2).

\section{English as a means of Global Communication}

In the present context of Globalization, English is the language of international communication as its use is widespread. It is used in almost all the countries in the modern world. Though English 
is originally the language spoken by the people of England, it is not limited to the territory of this country alone. People of all nationalities, ethnicity, religion, culture, profession and career have now begun to use this language as a common means of communication. English has been considered to be the first global lingua franca. In today's world, the English language has become a part and parcel of communication that takes place in every professional field. In other words, it has become a language of interpersonal communication, business, science, information technology and entertainment. Naved [11] states, "English is the primary language of not only countries actively touched by British imperialism but also many business and cultural spheres dominated by those countries. It is the language of Hollywood, and international banking and business "(P.1).

Day by day, the popularity of the English language is increasing in the present day world. The number of people learning this language is growing at a lightning speed all over the world. As cited by Pasinato [12], Graddoll [3] stresses:

...There will be two billion people speaking or learning English within a decade. For the conomists, English is the language of globalization among other nouns, everywhere anywhere today and most certainly tomorrow, English is to be present in the life of every citizen around the globe. It is the main tool for operating in most fields; Internet, banking, travelling (P.2).

\section{English as a means of Communication in Nepal}

English has a very important status as a means of communication in official context in Nepal. It has a significant status in journalism, education, science and technology. Citing various other scholars as mentioned below, Giri [2] quotes Khati [2] and states, "In Nepali academia, over 85\% of academic proceedings take place in English. Likewise, in Nepali mass communication, English has become one of the most dominant languages in print as well as electronic media," Yadav [2] pointed out " $19 \%$ of the total porgramme time of Radio Nepal and $24 \%$ of total progaramme time on Nepal TV was given to English Language". Similarly, Verma [2] reported, " $25 \%$ of news dailies were in English". More recently, Humagain [2] and Pokhrel [2] reported, "With all print media combined (i.e. dailies, weeklies and fortnightlies and monthlies), $40 \%$ of all materials are published in English and the number is increasing" [Giri 2, P.195].

Day after day, the English language is gaining more and more popularity. Its use has been widespread. There has been a remarkable improvement in its status as well. Gradually it is capturing the position of the second language, the one a learner learns or acquires immediately after he or she has acquired his or her first language or mother tongue. As cited by Giri [2], Greenbaum [2], suggests that, in the last few decades, English has been filling at least some of the functions of a second language in a country that has several indigenous languages. It dominates the print media and is used by the electronic media and some Nepalese turn to English for their creative writing.

The English language has been used as a medium of instruction in all the levels of education in Nepal for several decades and now it has been an inseparable part of the Nepalese education system. English is the preferred medium of instruction in most disciplines at Trubhuwan University and that English was the principal language of private schools. Citing Awasthi [2] and Karn [2], Giri [2] remarks that fictional literacy and the ability to communicate using English are not only desirable in education, but they are also indispensable because almost all academic discourse is carried out in the English language in the universities (P.196). 


\section{English as a means of Communication in Engineering}

The English language is the only medium of communication in the examinations in the engineering institutes in Nepal. Almost all the books that the students of engineering have to follow in order to enriching their minds and broadening their knowledge in their respective fields of specialization are imported from the foreign countries. As they are written by foreign writers and published by the foreign publishers, they are in the English language itself. Even the books, research articles, research papers, thesis, reports and proposals written by the Nepalese scholars and writers are mostly found in this very language. In this way, the students of engineering, no matter whichever subject and faculty of engineering they might belong to, they need to possess a sound knowledge of English to enable themselves to read these scholarly works to understand and acquire information from them.

At present, English and engineering education have become just like nail and flesh in the context of Nepal. We find English incorporated in the curriculum of engineering from the very beginning. The reason why English has remained so intact and integral part of engineering education in Nepal is not because the experts involved in designing curriculum for engineering intended to include it as one of the compulsory subjects just as a show piece or an ornament but because they felt the necessity of the English language for engineering communication.

Though we have Nepali as a language of common use, it has its access as a means of communication within limited areas within the territory of Nepal alone. It has not been fully developed so as to be used as a means of scientific and technological communication. Malla [10] states "...had Nepali been adequate for transmission of science and technology and for international communication, there would have been no functional need for learning English" (P.12).

Nepal is still a very backward nation in the field of science and technology. There are many things that Nepal needs to do in this field. We are still at the stage of infancy in the vast world of scientific and technological achievement compared to the progress that the other developed countries in the world have made so far. At this initial stage, we need to import scientific and technological knowledge through our younger generations by educating them in English and make them fully equipped with the necessary knowledge as well as skills in this field.

In order to equip our young generations with the latest scientific and technological knowledge and skills, the English language can be the only convenient means for us. Khanal [7] puts it:

...I am aware though, of the ambiguity to which English as a study is being subjected in the evolving scheme of our national life. But I believe that as we open up to the ruthlessly competitive modern world politically and culturally, English should continue to serve our leading citizens as a necessary window of intellectual and cultural ventilation (p.43).

English serves as one of the most indispensable tools for acquiring scientific and technological information and skills. It is the language widely used all over the world for publishing textbooks, reports, journals and articles based on scientific researches carried out by the scholars and researches in the field of scientific and technological innovation. In the words of Malla [10], "English is necessary mainly as a library language - language to have an access to textbooks, lectures and Journals "(P. 16). 
It is almost impossible for the nation like ours to achieve scientific and technological access without English for it is one of the most pervasive as well as powerful medium of communication. Without it, we cannot even imagine the development of our scientific and technical education that we desperately need for the development of our nation. Malla [10] suggests that the promotion of technical education, a profound objective of the education plan, is not possible without English. In fact, English is one of the preconditions for promoting technical education (P.18).

As English is the source language which enables our young students and scholars involved in the study of engineering to gain knowledge produced and explored by the genius of the engineering field, it occupies a very important position. In the words of Knanal [6], "Without using English in the present context of the country, the teaching and learning of any scientific and technical subject like engineering is not possible" (P.1).

\subsection{English for the Employability of Engineering Graduates}

Even after the completion of their academic career, the students of engineering need to possess the sufficient communicative skills in English in order to get employment. Right from the moment they leave their colleges or universities, they begin to seek jobs appropriate to their subject of specializations in engineering. For seeking job, they need to read notices and advertisements announcing job vacancies published in the English language. They need to submit their letter of job applications, bio-data (resume), written in standard English, During the job interview, they need to display how efficient communicators they are in the English language. Their written and spoken English is put to the test. Their success and failure in getting the job for which they have applied usually depends on their proficiency in English. Joshi [5] states, "When engineering students graduate from the college and become real engineers, they will find that English appears even more crucial than it used to be" (P.50).

Those candidates who are efficient orators and writers will be given the topmost priority. They have great possibility of being selected in the job interview. But the chance for those candidates whose communicative proficiency in English is shaky is usually thin. They are often the losers in the battles they fight for the sake of acquiring job.

\subsection{English for the Execution of Engineering Jobs}

As the engineers have international job markets, they need to prove that they are deserving candidates for grabbing those job opportunities. Just completing their courses and getting through examinations conducted by the engineering institutes with good scores will not be sufficient for them. In the words of Thaky [15], "Multilingual skills are considered a salient element in the make-up of the new global engineer"(P.1). Even the candidates, who have secured distinction throughout their academic career in engineering, may be unsuccessful in executing their Jobs unless they possess the high level of proficiency in communication in English. Reimer [13] remarks, "There is ample evidence that graduate engineers lack the required standard of communication skills." In course of executing their jobs, the engineers are required to exhibit their high caliber in communication in English. Their written as well as oral proficiency is under the rigorous test regularly and frequently. 


\section{Conclusion}

Communication is a specialized universal human characteristics. For Communication, they use language of immensely varying forms and nature. English being one of the languages of wider circulation, it has emerged as a means of global communication covering a wide range of fields and professions. In Nepal also, English has been taught as a subject from the very lowermost level to the university level of education and is used as a medium. In the field of engineering profession also, it serves as a most popular means of communication. It is an integral part of professional communication in engineering in Nepal. English has a vital role to play in the career of engineers. They need English throughout their Engineering career from the moment they start it as a student until they get retirement as an engineer.

\section{References}

[1] Bhattarai GR and Gautam GR (2007), The Proposed ELT Survey; Redefining status and Role of English in Nepal. Journal of NELTA, 1 \& 2 : 32-35.

[2] Giri RA (2014), Changing Faces of English: why English is not a Foreign language in Nepal. Journal of world Languages, Australia; Routledge, Taylor \& Francis Group, 192-209.

[3] Graddoll D (1997), The Future of English? A Guide to Forecasting the Popularity of the English Language in the $21^{\text {st }}$ Century. London: British Council.

[4] Hurford JR (2008), The Evolution of Human Communication and Language, 249-264 (retrieved date: $28^{\text {th }}$ January, 2016).

[5] Joshi DH (2013), Importance of English Language for Students of Engineering. Gujrat, India: VSRD International Journal of Technical \& Non-Technical Research, 4, 3: 50-56.

[6] Khanal RN (2010/11), English for Profession Specific Learners (An Analysis in Relation to Engineering). Journal of Institute of Engineering, 8(1 \& 2) : 311-314.

[7] Khanal YN (1996), World Culture in Making: Nepal after Democratic Restoration. Kathmandu: Ratna Pustak Bhandar.

[8] Konar N (2010), Communication Skills for Professionals. Delhi: Phl Learning Private Limited.

[9] Kumar \& Lata (2012), Communication Skills. New Delhi: Oxford University Press.

[10] Malla KP (1977). English in Nepalese Education. Kathmandu: Ratna Pustak Bhandar.

[11] Naved, Z (2015), The Importance of English Language in Today's World (retrieved on 25/12/2015).

[12] Pasinato DA (2016), The English Language and the Globalization. (retrieved on 28/01/2016), $1-21$.

[13] Reimer MJ (2002), English and Communication Skills for Global Engineer. Australia: Global Journal of Engineering Education, 6(1) : 91-100.

[14] Rizvi MA (2008), Effective Technical Communication. New Delhi; Tata Mc Graw-Hill Publishing Company Limited.

[15] Thaky P (2014), Importance of English and Communication Skills for Technical Professionals. IJSR International Journal of Scientific Research, 211 (3 \&4) : 1-8. 